\title{
Europe chooses cosmic radiation project
}

Paris. Cobras/Samba, a new satellite designed to measure cosmic background radiation over the whole sky, has been given top ranking over four rival projects for the next 'medium-sized' space mission of the European Space Agency (ESA), which is scheduled for launch around 2004.

The project was selected at a meeting in Paris last week of ESA's space science advisory committee (SSAC). It will be the third medium-sized mission within ESA's Horizon 2000 science programme, which began in 1985 and is scheduled to run until 2015.

Such missions, which are budgeted at around ECU345 million (US\$424 million) each, complement the larger cornerstone

\section{Pentagon delay on asteroid mission}

Washington. Funding for a US military project to send an advanced spacecraft to rendezvous with several asteroids is being held up within the Pentagon, even though Congress agreed to provide $\mathbf{\$ 2 0}$ million for the mission last year and the Department of Defense gave it the official go-ahead. Work on Clementine 2 has effectively stopped while project managers and their political allies try to persuade the Air Force and the Pentagon comptroller to release the money.

Sources in Congress say they do not know why the funds are being withheld, but some suspect that the Defense Department is trying to 'reprogramme' money to support operations in Bosnia. Members of the Clementine team say that funding problems of this type are not uncommon with advanced military technology projects.

Clementine 2 is scheduled to be launched in May 1998. The plan calls for a spacecraft to fly past three or more near-Earth asteroids, and to release small probes to crash into their surfaces, so that sensors on the main spacecraft can observe the impacts.

Like Clementine 1, which mapped the Moon in 1994, Clementine 2 is intended chiefly to test advanced spacecraft technologies developed for strategic defence and other purposes. One important objective is to prove the ability to track and rendezvous with fast-moving targets in space. The mission also supports a military programme for 'planetary defence' - protecting the planet against possible extraterrestrial threats.

The Air Force's Phillips Laboratory in New Mexico has lead responsibility for Clementine 2, with the Naval Research Laboratory in Washington DC responsible for integrating the spacecraft, and the Lawrence Livermore National Laboratory in California developing sensors.

Project engineers completed a 'concept design review' in March. But the hold-up in funding has prevented further progress. A 'preliminary design review' is due in July missions of about ECU625 million that form the backbone of the programme.

The Cobras/Samba mission would cost about ECU340 million, and would have 10 times greater sensitivity and 50 times the angular resolution of the Cosmic Background Explorer (COBE). It was COBE which, in 1992, discovered temperature irregularities in the cosmic background radiation field caused by primordial perturbations occurring within $10^{-35}$ seconds of the Big Bang.

The new satellite would build on these results. It would aim to establish whether the large-scale uniformity of the Universe resulted from an early period of expansion

and a 'critical design review' in November; that schedule is now in jeopardy and project engineers have identified several back-up options in case the launch is delayed. A slip of several months, to September 1998, would in fact offer some advantages, including a shorter mission duration (9.5 rather than 13 months) and eliminating the need to use the Earth's gravity to give the spacecraft a boost to reach its asteroid targets.

But the September 1998 date would leave no room for slips in the schedule, and the spacecraft would not have as good a viewing angle once it reached the asteroids. Additional delays would also make it more difficult to keep the project within its budget of approximately $\$ 100$ million.

The funding hiatus could also slow down the work of an informal Clementine 2 science advisory team headed by Eugene Shoemaker of the Lowell Observatory in Arizona, which, among other tasks, has to continue refining orbits for the target asteroids. The team also needs to begin selecting the science instruments that will fly on the spacecraft.

Shoemaker still hopes that the National Aeronautics and Space Administration (NASA) will participate in the project, as it did in Clementine 1, by sponsoring a formal scientific advisory team. But NASA officials say this is unlikely, given current funding constraints. NASA also has its own low-cost asteroid mission scheduled for 1998 and NEAR (Near-Earth Asteroid Rendezvous), due to meet the large asteroid Eros in 1999.

No one is certain how and when the funding issue will be resolved. James Muncy, a congressional staff member who works on space issues for Dana Rohrabacher (Republican, California), says that several members of both the House and the Senate are working on the problem. He adds that it is simply a matter of continuing to put pressure on Pentagon officials until they release the money.

Tony Reichhardt known as inflation, and it would look for primordial irregularities that gave rise to galaxies and other structures in the Universe.

As well as providing information on the physics of the early Universe, such measurements can also be used to estimate many astrophysical parameters - such as the Hubble constant - to within a few per cent.

The choice of Cobras/Samba came at the end of a two-day meeting in Paris, at which details of the five projects were presented to about 250 scientists. The advisory committee's recommendations will now go to ESA's science programme committee, which meets in early June. The latter panel, which makes the final decision on the choice of the mission, has never overturned a recommendation by the SSAC.

But any victory celebrations will be dampened by the knowledge that the winning mission must find ways to reduce its costs by 10 per cent, which will mean delaying the launch from the scheduled date of 2003 by at least one year.

ESA decided earlier this year that this mission would be used as a pilot test to assess what savings could be made in mission costs, after the agency had been forced by member states to achieve an annual reduction of around 3 per cent in ESA's science budget (see Nature 379, 476; 1996).

Cobras/Samba's suitability for this pilot test seemed to have acted in its favour in the competition with its main rival, Intermarsnet, a project that included three landers built by the US National Aeronautics and Space Administration and a datarelay satellite built by ESA.

According to an ESA official, Cobras/ Samba scored points for the fact that its proposed costs are already well within budget, while its design lends itself to a relatively straightforward pilot phase.

In contrast, Intermarsnet was the most expensive of all the five finalists. ESA was also concerned that it would be unable to meet NASA's scheduled 2003 launch date for the mission, given the delays that would be needed to carry out the savings pilot test.

Intermarsnet itself prevailed over MORO - a lunar orbiting observatory aimed at studying the Moon's surface and interior - as the choice of planetary scientists. In the astronomy field, Cobras/Samba was given preference over STARS, a mission to measure the internal structure of a wide range of stars by fine analysis of fluctuations in their brightness.

The remaining candidate, STEP, was aimed at testing the equivalence principle and carrying out a broad range of experiments in fundamental physics. But the proposal suffered from uncertainty about US and French plans for a similar satellite, and the fundamental physics group decided not to push its candidacy. 


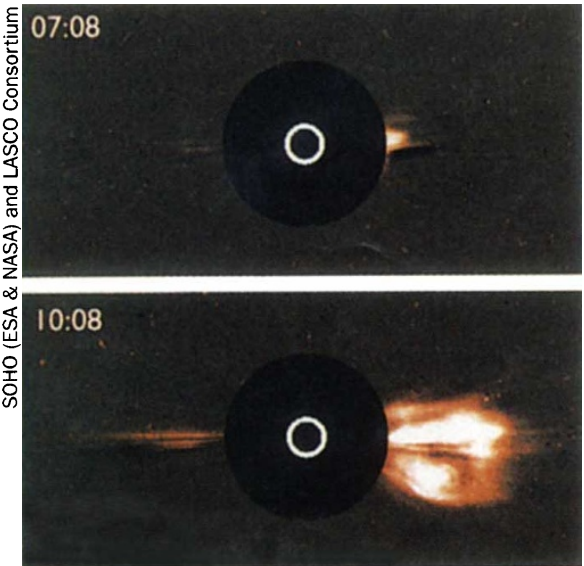

$13: 14$

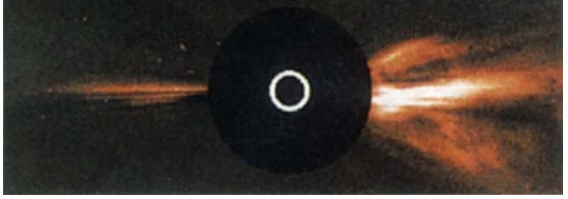

Images released today from the joint ESANASA SOHO project show a coronal mass ejection: billions of tonnes of gas burst out of the Sun at $550 \mathrm{~km}$ per second.

- Cobras/Samba and Intermarsnet entered the final selection round neck-and-neck according to scientists at the meeting. In particular, the meeting had to digest the significance of a recent US announcement that it intended to launch a similar mission to Cobras/Samba, called MAP.

But the Paris meeting concluded that MAP was "definitely an inferior mission", according to a senior official of the space science programme, who says that the performance of the US satellite had been "overstated".

In order to prevent the portfolio of ESA's missions early in the next decade being dominated by astronomy, the SSAC recommended that the next cornerstone mission be reserved for a planned mission to Mercury that would include an orbiting observatory and a landing craft (see Nature 371, 643; 1994). It also recommended that the next medium-sized mission be reserved for a project on Solar System research. "The success of Cobras/Sampas has been paid at a certain cost by the astronomy community," says one ESA official.

Declan Butler

\section{German research loses immunity to cuts}

Munich. German research minister Jürgen Rüttgers has not maintained the financial advantage he gained for his ministry last year when he secured an above-average budget rise of 2.8 per cent for 1996 over the 1995 level. The research ministry will not be exempt from a new round of budget cuts being imposed on all government spending as part of an emergency budget, introduced to combat the country's budget deficit resulting largely from the continued costs of reunification.

The federal government agreed last

\section{Geneticist leaves Cambridge for industrial research post}

London. One of Britain's leading geneticists is leaving a senior academic post to head the genetics research activities of SmithKline Beecham (SB), the world's tenth largest pharmaceutical company, which says that it is planning to base all future pharmaceutical and diagnostic products on knowledge of the human genome.

Peter Goodfellow, Arthur Balfour professor of genetics at the University of Cambridge, and well-known for a wide variety of contributions to genetics research - ranging from somatic cell genetics to sex determination - has announced his resignation, and will join SB at its main British research site at Harlow, outside London, at the beginning of July.

Goodfellow's arrival is being seen by the company not only as laying an important cornerstone for its genomics strategy, but also as evidence of a growing overlap between academic and industrial researchers, the distance between which has traditionally been greater in the United Kingdom than in countries such as the United States.

One aspect of this overlap, according to some, is that the cost of advanced research facilities in fields such as DNA sequencing is now so high that the private sector can offer more attractive basic research facilities than the academic sector. Goodfellow, for example, will have access to the privately held database of genomic sequences built up by Human Genome Sciences and the Institute for Genomic Research in Rockville, Maryland, in which SB has a major share.

"We are delighted to be bringing someone of Goodfellow's stature into the organization," says George Poste, director of research and development for the pharmaceutical company, formed in 1989 out of a merger between the US company SmithKline French and Britain's Beecham.

Poste has been largely responsible for a strategy that aims to make knowledge of the genome the starting point for all new diag-

Friday that the 1996 research budget of DM15.6 billion (US\$10.3 billon) now should be trimmed by two per cent for the rest of the year. Rüttgers says that new initiatives, such as the biotechnology and multimedia programmes, will be protected. But he has yet to say where he anticipated the cuts will fall. According to a spokeswoman for the ministry, such decisions are unlikely to be made before the summer, when the first round of talks regarding the 1997 research budget are due to be concluded. nostic and therapeutic products in SB by the end of the decade. Sequencing the human genome, he argues, is only the first step; equally difficult is learning how to exploit the knowledge that this produces. "The whole world of science has to spend a lot of time trying to assess the functional role of genes," he says. "Goodfellow's appointment is an expression of that reality."

Genomic knowledge, he says, will not be used only as the basis of new diagnostic tests and potential therapies. Another potential application is in the testing of new drugs before approval by regulatory authorities, attempting to understand the 'pharmacogenetic' basis of drug response at the molecular level - in other words why different people respond to drugs in different ways.

Goodfellow already has industrial experience. He has, for example, been a consultant for Amersham International and a founding member of the scientific advisory board of Sequana Therapeutics in California, which recently announced the discovery of the 'tubby' gene responsible for one type of obesity in mice (see Nature 380, 534 538 ; 1996).

$\mathrm{He}$ expresses both regret and relief at leaving the academic environment. "I've had a wonderful time at Cambridge,"

at Goodfellow: regret and says. "But there

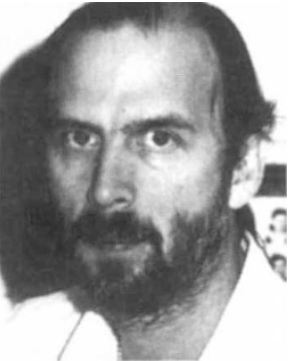

have been constraints. It has been a strain to maintain the infrastructure needed to carry out internationally competitive research and the financial restraints have been getting worse."

He will also be giving up the sex determination work that he has been involved in for the past ten years. But at the same time, he says that his new UK-based post, in which as a senior vice-president for research and development he will be one of the managers responsible for SB's worldwide research, will involve "taking the sort of science that we do in universities into an industrial context".

Meanwhile, Poste says that he also hopes that Goodfellow's arrival at the company will help to boost the morale of its scientists in Britain which, he admits, was badly shaken by his decision last year to close down part of its microbiological activity, and which is further undermined by talk of future job losses among research teams considered insufficiently productive. "This sends a signal that we are committed to the long-haul in the United Kingdom," he says.

David Dickson 